\title{
Potential of a planarian model to study certain aspects of anti-Parkinsonism drugs
}

\author{
Robert B. Raffa ${ }^{1 \#}$, Jeff Danah ${ }^{1}$, Christopher S. Tallarida ${ }^{1}$, Carrie Zimmerman $^{1}$, Grace Gill ${ }^{1}$, \\ Steven J. Baron ${ }^{1}$, Scott M. Rawls ${ }^{2}$
}

${ }^{1}$ Temple University School of Pharmacy, Philadelphia, USA; ${ }^{*}$ Corresponding Author: robert.raffa@temple.edu

${ }^{2}$ Center for Substance Abuse Research and Temple University School of Medicine, Philadelphia, USA

Received 15 February 2013; revised 30 March 2013; accepted 22 April 2013

Copyright (C) 2013 Robert B. Raffa et al. This is an open access article distributed under the Creative Commons Attribution License, which permits unrestricted use, distribution, and reproduction in any medium, provided the original work is properly cited.

\begin{abstract}
We previously created and investigated a planarian model for the study of drug action, abuse, physical dependence, receptor affinity, the toxicity of heavy metals in wastewater, and seizures. For the present pilot study, we investigated the possibility that this model might be useful for studying certain aspects of drugs used in treatment of Parkinson disease. For the first step, we were interested in finding an in vivo metric for the inhibition of L-DOPA by an inhibitor of DOPA decarboxylase. The direct clinical relevance of the endpoint was of secondary concern during this preliminary phase of model development. Two metrics were explored: LDOPA-induced inhibition of motility (locomotor velocity) and dopamine-mediated toxicity, which was quantified using a Kaplan-Meier survival curve. L-DOPA produced both dose- and timerelated toxicity. The water-soluble DOPA decarboxylase inhibitor benserazide dose-dependently inhibited the effect of L-DOPA, as manifested by a leftward shift in the Kaplan-Meier curve. Additional work was initiated using the more sensitive and a graded metric of spontaneous locomotor velocity. The encouraging results of this pilot study suggest that: 1) planarians contain DOPA decarboxylase or an equivalent enzyme, and 2) the planarian model might be useful for the study of certain aspects of anti-Parkinsonism pharmacotherapy.
\end{abstract}

Keywords: L-DOPA; Benserazide; Planarians

*All authors contributed significantly to this study and there are no conflicts of interest.

\section{INTRODUCTION}

Parkinson disease (PD) is manifested as generalized abnormalities in locomotor movements (hypokinesias) (paralysis agitans) such as a stooped posture, difficulty in initiating and stopping walking, a short and shuffling gait, and a tendency to fall over [1-6]. The mean age of $\mathrm{PD}$ onset is about 60 years [7]; its prevalence is approximately $1 \%$ of those older than 65 years [8]. The disorder occurs throughout the world [9].

Post-mortem brains of PD patients have a decreased level of dopamine [10] that correlates with the loss of dopaminergic neurons within the substantia nigra pars compacta $(\mathrm{SNpc})$ and degeneration of nerve terminals in the corpus striatum (basal ganglia) (Figure 1) [1]. Because the basal ganglia participate in regulation of neuronal transmission from the cerebral cortex to motor neurons of the spinal cord, decreased levels of dopamine disrupt the balance between dopamine and other neurotransmitters that are involved in a coordinated locomotor activity, including acetylcholine, GABA ( $\gamma$-aminobutyric acid), glutamate, 5-HT (5-hydroxytryptamine or serotonin), norepinephrine, and neuropeptides in striatal interneurons [11]. The SNpc target neurons express both major 7-TM-GPCR (seven-transmembrane G proteincoupled receptor) dopamine receptor (DAR) types: excitatory DAR $\mathrm{D}_{1} D R D 1$ (transduced by stimulated formation of cAMP and phosphatidyl inositol hydrolysis) and inhibitory DAR $\mathrm{D}_{2} D R D 2$ (transduced by decreased cAMP and modulation of $\mathrm{K}^{+}$and $\mathrm{Ca}^{2+}$ currents). In experimentally-lesioned animals, damage to the nigrostriatal pathway results in a hyperactivity of the remaining dopaminergic neurons, increased transmitter turnover rate, and state of denervation super sensitivity [12].

Current pharmacologic management of PD involves a restoration of the balance between dopamine and other neurotransmitters, most commonly by replenishment of dopamine [13]. Since direct administration of dopamine 


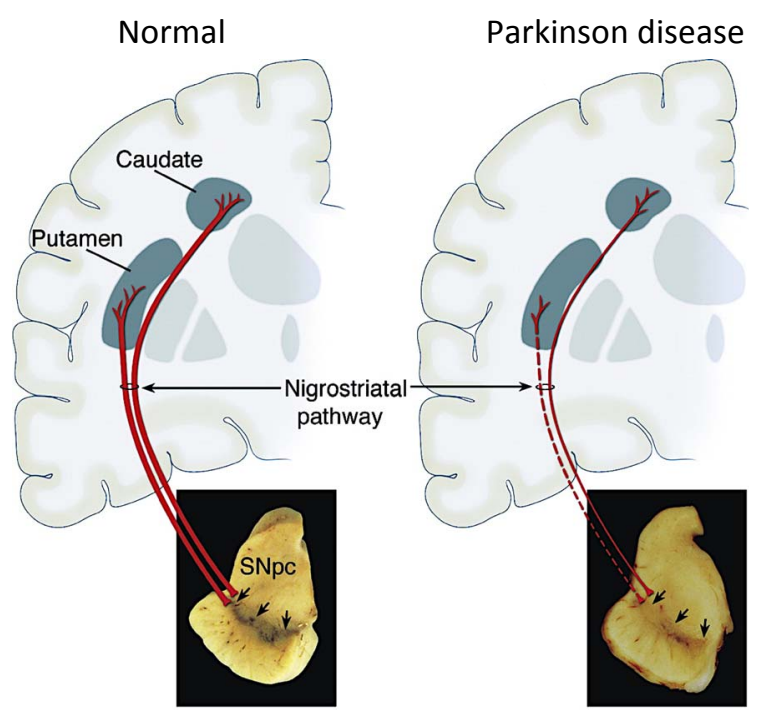

Figure 1. Schematic representation of the normal nigrostriatal pathway and marked degeneration in Parkinson disease. SNpc (substantia nigra pars compacta). Reprinted from Dauer et al. [1] with permission.

is ineffective or inefficient, because it does not readily cross the blood-brain barrier, indirect approaches are used. The most common is administration of the amino acid levodopa (L-DOPA) [13,14]. L-DOPA enters the brain by active amino acid transport systems [15] and is then converted to dopamine by the enzyme L-aromatic amino acid decarboxylase (DOPA decarboxylase) [16].

There are several animal models of PD [1]. Most of the models use mammals and are generally both timeand resource-intensive. We here report a convenient and facile non-mammalian model for in vivo demonstration and quantitative assessment of DOPA decarboxylase or an equivalent enzyme activity in a species with primitive nervous system and mammalian-analogous neurotransmitter and 2nd messenger systems [17-26]. The model is useful for the study of drug action and for physiological aspects of drug abuse [27-43].

\section{MATERIALS AND METHODS}

\subsection{Animals and Chemicals}

The planarians (Dugesia dorotocephala) were obtained from Carolina Biological Supply Co. (Burlington, $\mathrm{NC})$. They were acclimated to laboratory conditions and were tested within $48 \mathrm{~h}$ of receipt. L-DOPA and benserazide (a competitive inhibitor of DOPA decarboxylase) were obtained from commercial sources and were prepared at the desired concentration in tap water. $\mathrm{N}=12$ per group.

\subsection{Testing}

Phase 1. In order to construct a survival Kaplan-Meier curve, planarians were placed individually into observation (petri) dishes that contained either water (as control) or L-DOPA at a concentration that had previously been established in pilot studies. Each of the groups was tested with or without benserazide. The number of the planarians remaining alive at specified times during the observation period was recorded.

Phase 2. In order to measure the $p \mathrm{LMV}$, as has been previously described [31], each planarian was placed individually into a clear plastic petri dish that was located over graph paper having gridlines that were spaced $0.5 \mathrm{~cm}$ apart in a square pattern. The dish contained either water as the control or L-DOPA at a concentration that was established in pilot studies. $p$ LMV was quantified by counting the number of gridlines that each planarian crossed or re-crossed during each minute over the observation period. The results are graphed as the group mean number of (re)crossings for each minute during the observation period.

\section{RESULTS}

Phase 1. Exposure of planarians to L-DOPA resulted in a dose- and time-dependent toxicity that was manifested by a decrease in number over the 2-h observation period. At each of the doses of L-DOPA, the effect of L-DOPA was attenuated by the DOPA decarboxylase inhibitor benserazide (see Figure 2).

Phase 2. Consistent with previous results [31], untreated planarians displayed a relatively constant and a near linear spontaneous locomotor activity ( $p \mathrm{LMV}$ ) of about 10 - 15 gridlines per minute over the entire obser-

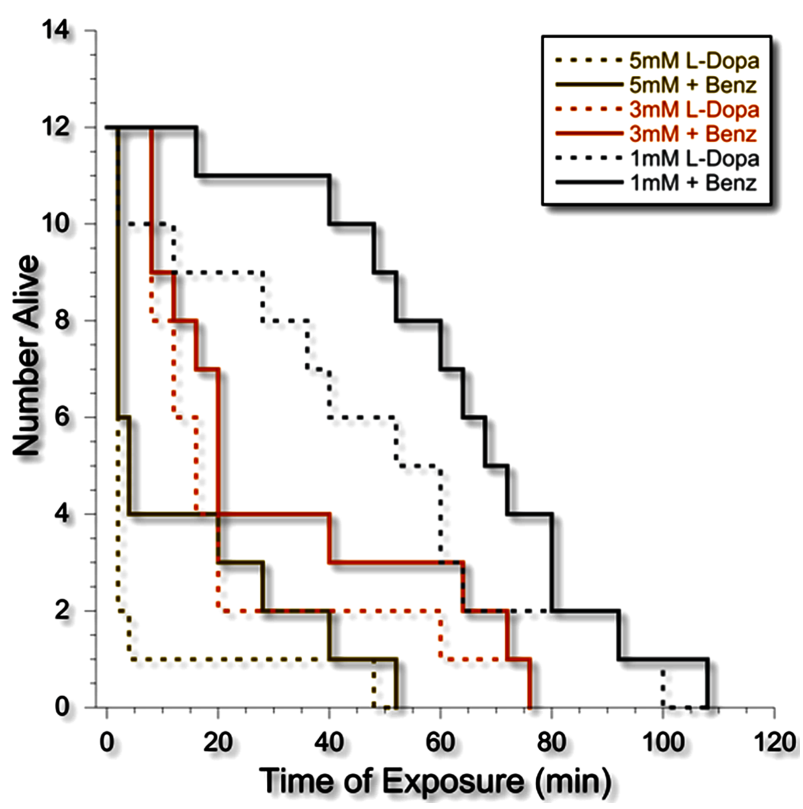

Figure 2. Kaplan-Meier survival curve of planarians exposed to L-DOPA alone (dotted lines) or L-DOPA plus benserazide (solid lines). 
vation period of 10 minutes. L-DOPA decreased the $p$ LMV. Importantly, the $p$ LMV in the presence of LDOPA was linear (see Figure 3).

\section{DISCUSSION}

The present work investigated the use of a simple in vivo planarian model in order to study the in vivo effect of L-DOPA, specifically, the metabolic conversion of L-DOPA by DOPA decarboxylase or the planarian equivalent. Planarians have a simple nervous system with mammalian-like neurotransmitter systems (e.g., [17,24, 26]), including dopaminergic. Therefore, they are the lowest form of extant animal that would display relevant dopaminergic-related neurotoxicity. They have been shown to respond with quantifiable dose-related behavioral changes to drug exposure or to withdrawal (e.g., $[17,19,21,22,25-27,30,33-34,37])$. We and others have used planarian models for investigation of drug action and related physiological processes (for a review, see the monograph [31]).

In the present study, the dose-related L-DOPA-induced (neuro)toxicity was attenuated by benserazide, which is an inhibitor of DOPA decarboxylase. It is used clinically together with L-DOPA in order to minimize the conversion of L-DOPA to dopamine in the periphery-thereby increasing the percent of the administered dose that is converted to dopamine in the CNS (Figure 4).

These results provide in vivo evidence for the presence and functional activity of DOPA decarboxylase or for an equivalent enzyme in planarians. A D. japonica aromatic amino acid decarboxylase-like activity (DjAADCA) gene,

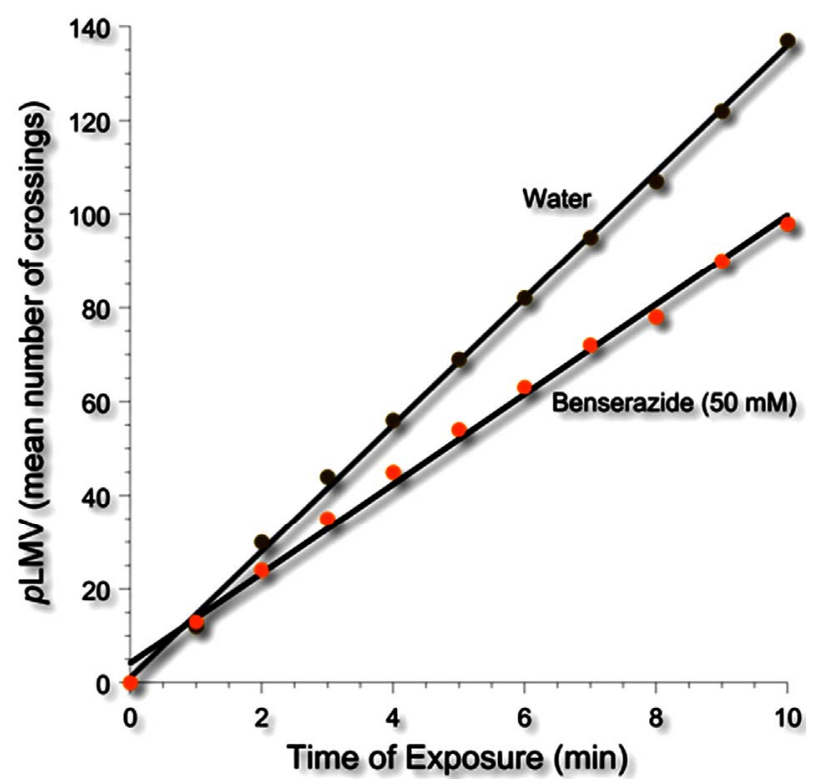

Figure 3. Spontaneous locomotor activity of planarians ( $p$ LMV) in water or the DOPA decarboxylase inhibitor benserazide (50 $\mathrm{mM})$.

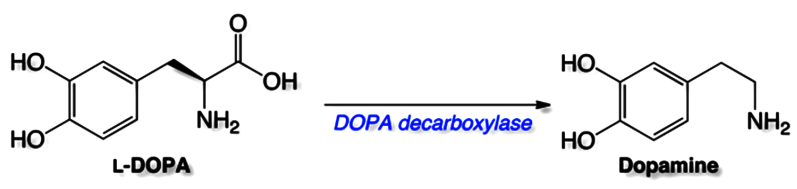

Figure 4. Conversion of L-DOPA to dopamine catalyzed by DOPA decarboxylase.

and mRNA and protein expression have been identified in D. japonica by Nishimura and colleagues [44]. It thus seems that $D$. dorotocephala shares the same or similar enzyme.

In summary, L-DOPA produced dose- and time-related lethality in planarians that was attenuated by a reversible inhibitor of DOPA decarboxylase (benserazide). These results are consistent with a previous demonstration of such an enzyme in planarians [44] and they support the use of a facile planarian model to study certain biochemical aspects of anti-Parkinson drugs.

\section{ACKNOWLEDGEMENTS}

The authors thank Timothy Shickley, Ph.D., for the suggestion of Planaria as a model. This work was supported by NIH grants DA15378 (RBR) and DA022694 (SMR).

\section{REFERENCES}

[1] Dauer, W. and Przedborski, S. (2003) Parkinson's disease: Mechanisms and models. Neuron, 39, 889-909. doi:10.1016/S0896-6273(03)00568-3

[2] Garcia Ruiz, P.J., Catalan, M.J. and Fernandez Carril, J. (2011) Initial motor symptoms of Parkinson disease. Neurologist, 17, S18-S20. doi:10.1097/NRL.0b013e31823966b4

[3] Lees, A.J., Hardy, J. and Revesz, T. (2009) Parkinson's disease. Lancet, 373, 2055-2066. doi:10.1016/S0140-6736(09)60492-X

[4] Hughes, A.J., Daniel, S.E., Kilford, L. and Lees, A.J. (1992) Accuracy of clinical diagnosis of idiopathic Parkinson's disease: A clinico-pathological study of 100 cases. Journal of Neurol Neurosurg Psychiatry, 55, 181-184. doi:10.1136/jnnp.55.3.181

[5] De Lau, L.M., Koudstaal, P.J., Hofman, A. and Breteler, M.M. (2006) Subjective complaints precede Parkinson disease: The rotterdam study. Archives of Neurology, 63, 362-365. doi:10.1001/archneur.63.3.noc50312

[6] Shahed, J. and Jankovic, J. (2007) Motor symptoms in Parkinson's disease. Handbook of Clinical Neurology, 83, 329-342. doi:10.1016/S0072-9752(07)83013-2

[7] Hoehn, M.M. and Yahr, M.D. (1967) Parkinsonism: Onset, progression and mortality. Neurology, 17, 427-442. doi:10.1212/WNL.17.5.427

[8] De Rijk, M.C., Breteler, M.M., Graveland, G.A., Ott, A., Grobbee, D.E., van der Meche, F.G. and Hofman, A. (1995) Prevalence of Parkinson's disease in the elderly: The Rotterdam study. Neurology, 45, 2143-2146. 
doi:10.1212/WNL.45.12.2143

[9] De Lau, L.M. and Breteler, M.M. (2006) Epidemiology of Parkinson's disease. The Lancet Neurology, 5, 525535. doi:10.1016/S1474-4422(06)70471-9

[10] Bernheimer, H., Birkmayer, W., Hornykiewicz, O., Jellinger, K. and Seitelberger, F. (1973) Brain dopamine and the syndromes of Parkinson and Huntington. Clinical, morphological and neurochemical correlations. Journal of the Neurological Sciences, 20, 415-455. doi:10.1016/0022-510X(73)90175-5

[11] Gilgun-Sherki, Y., Hellmann, M., Melamedm E., and Offen, D. (2004) The role of neurotransmitters and neuropeptides in Parkinson's disease: Implications for therapy. Drugs of the Future, 29, 1261. doi:10.1358/dof.2004.029.12.869227

[12] Trugman, J. M. and James, C. L. (1992) Rapid development of dopaminergic supersensitivity in reserpinetreated rats demonstrated with ${ }^{14} \mathrm{C}$-2-deoxyglucose autoradiography. The Journal of Neuroscience, 12, 28752879.

[13] Huse, D.M., Castelli-Haley, J., Orsini, L.S., Lenhart G. and Abdalla, J.A. (2006) Patterns of initial pharmacotherapy for Parkinson's disease in the United States. Journal of Geriatric Psychiatry and Neurology, 19, 9197. doi:10.1177/0891988706286512

[14] Hornykiewicz, O. (2002) L-DOPA: From a biologically inactive amino acid to a successful therapeutic agent. Amino Acids, 23, 65-70. doi:10.1007/s00726-001-0111-9

[15] Wade, L.A. and Katzman, R. (1975) Synthetic amino acids and the nature of L-DOPA transport at the bloodbrain barrier. Journal of Neurochemistry, 25, 837-842. doi:10.1111/j.1471-4159.1975.tb04415.x

[16] Melamed, E., Hefti, F., Pettibone, D.J., Liebman, J. and Wurtman, R.J. (1981) Aromatic L-amino acid decarboxylase in rat corpus striatum: Implications for action of L-dopa in Parkinsonism. Neurology, 31, 651-655. doi:10.1212/WNL.31.6.651

[17] Algeri, S., Carolei, A., Ferretti, P., Gallone, C., Palladini, G. and Venturini, G. (1983) Effects of dopaminergic agents on monoamine levels and motor behaviour in planaria. Comparative Biochemistry and Physiology Part $C$, 74, 27-29. doi:10.1016/0742-8413(83)90142-1

[18] Buttarelli, F.R., Pontieri, F.E., Margotta, V. and Palladini, G. (2000) Acetylcholine/dopamine interaction in planaria. Comparative Biochemistry and Physiology Part C, 125, 225- 231.

[19] Carolei, A., Margotta, V. andPalladini, G. (1975) Proposal of a new model with dopaminergic-cholinergic interactions for neuropharmacological investigations. Neuropsychobiology, 1, 355-364. doi:10.1159/000117512

[20] Palladini, G., Margotta, V., Carolei, A., Chiarini, F., Del Piano, M., Lauro, G.M., Medolago-Albani, L. and Venturini, G. (1983) The cerebrum of Dugesia gonocephala s.1. Platyhelminthes, Turbellaria, Tricladida. Morphological and functional observations. Journal für Hirnforschung, 24, 165-172

[21] Palladini, G., Ruggeri, S., Stocchi, F., De Pandis, M.F., Venturini, G. and Margotta, V. (1996) A pharmacological study of cocaine activity in planaria. Comparative Biochemistry and Physiology Part $C, \mathbf{1 1 5}, 41-45$. doi:10.1016/S0742-8413(96)00053-9

[22] Passarelli, F., Merante, A., Pontieri, F.E., Margotta, V., Venturini, G. and Palladini, G. (1999) Opioid-dopamine interaction in planaria: A behavioral study. Comparative Biochemistry and Physiology Part C, 124, 51-55. doi:10.1016/S0742-8413(99)00048-1

[23] Ribeiro, P., El-Shehabi, F. and Patocka, N. (2005) Classical transmitters and their receptors in flatworms. Parasitology, 131, S19-40. doi:10.1017/S0031182005008565

[24] Venturini, G., Carolei, A., Palladini, G., Margotta, V. and Lauro, M.G. (1983) Radioimmunological and immunocytochemical demonstration of Met-enkephalin in planaria. Comparative Biochemistry and Physiology Part $C$, 74, 23-25. doi:10.1016/0742-8413(83)90141-X

[25] Venturini, G., Stocchi, F., Margotta, V., Ruggieri, S., Bravi, D., Bellantuono, P. and Palladini, G. (1989) A pharmacological study of dopaminergic receptors in planaria. Neuropharmacology, 28, 1377-1382. doi:10.1016/0028-3908(89)90013-0

[26] Welsh, J.H. and Williams, L.D. (1970) Monoamine-containing neurons in planaria. Journal of Comparative Neurology, 138, 103-115. doi:10.1002/cne.901380108

[27] Raffa, R.B. and Desai, P. (2005) Description and quantification of cocaine withdrawal signs in Planaria. Brain Research, 1032, 200-202. doi:10.1016/j.brainres.2004.10.052

[28] Raffa, R.B., Finno, K.E., Tallarida, C.S. and Rawls, S.M. (2010) Topiramate-antagonism of L-glutamate-induced paroxysms in planarians. European Journal of Pharmacology, 649, 150-153. doi:10.1016/j.ejphar.2010.09.021

[29] Raffa, R.B., Holland, L.J. and Schulingkamp R.J. (2001) Quantitative assessment of dopamine $\mathrm{D}_{2}$ antagonist activity using invertebrate (Planaria) locomotion as a functional endpoint. Journal of Pharmacological and Toxicological Methods, 45, 223-226. doi:10.1016/S1056-8719(01)00152-6

[30] Raffa, R.B. and Martley, A.F. (2005) Amphetamine-induced increase in planarian locomotor activity and block by UV light. Brain Research, 1031, 138-140. doi:10.1016/j.brainres.2004.10.051

[31] Raffa, R.B. and Rawls, S.M. (2008) Planaria: A Model for Drug Action and Abuse. Landes Bioscience.

[32] Raffa, R.B., Robinson, M.J. and Tallarida, R.J. (1985) Ultraviolet light-induced photorelaxation of agonist-contracted rabbit aorta: Further characterization and the estimation of drug-receptor rate constants. Drug Development Research, 5, 359-369. doi:10.1002/ddr.430050409

[33] Raffa, R.B., Stagliano, G.W. and Umeda, S. (2003) Kappa-opioid withdrawal in Planaria. Neuroscience Letters, 349, 139-142. doi:10.1016/S0304-3940(03)00814-0

[34] Raffa, R.B. andValdez, J.M. (2001) Cocaine withdrawal in Planaria. European Journal of Pharmacology, 430, 143-145. doi:10.1016/S0014-2999(01)01358-9

[35] Raffa, R.B., Valdez, J.M., Holland, L.J. and Schulingkamp, R.J. (2000) Energy-dependent UV light-induced disruption of (-)sulpiride antagonism of dopamine. Euro- 
pean Journal of Pharmacology, 406, R11-R12. doi:10.1016/S0014-2999(00)00730-5

[36] Rawls, S.M., Thomas, T., Adeola, M., Patil, T., Raymondi, N., Poles, A., Loo, M. and Raffa, R.B. (2009) Topiramate antagonizes NMDA- and AMPA-induced seizure-like activity in planarians. Pharmacology Biochemistry and Behavior, 93, 363-367. doi:10.1016/j.pbb.2009.05.005

[37] Umeda, S., Stagliano, G.W. and Raffa, R.B. (2004) Cocaine and kappa-opioid withdrawal in Planaria blocked by D-, but not L-, glucose. Brain Reseatch, 1018, 181185. doi:10.1016/j.brainres.2004.05.057

[38] Pagan, O.R., Baker, D., Deats, S., Montgomery, E., Tenaglia, M., Randolph, C., Kotturu, D., Tallarida, C., Bach, D., Wilk, G., Rawlsm S. and Raffa, R.B. (2012) Planarians in pharmacology: Parthenolide is a specific behavioral antagonist of cocaine in the planarian Girardia tigrina. The International Journal of Developmental Biology, 56, 193-196. doi:10.1387/ijdb.113486op

[39] Pagan, O.R., Eterovic, V.A., Garcia, M., Vergne, D., Basilio, C.M., Rodriguez, A.D. and Hann, R.M. (2001) Cembranoid and long-chain alkanol sites on the nicotinic acetylcholine receptor and their allosteric interaction. Biochemistry, 40, 11121-11130. doi:10.1021/bi0112255

[40] Pagan, O.R., Rowlands, A.L., Azam, M., Urban, K.R., Bidja, A.H., Roy, D.M., Feeney, R.B. and Afshari, L.K.
(2008) Reversal of cocaine-induced planarian behavior by parthenolide and related sesquiterpene lactones. Pharmacology Biochemistry and Behavior, 89, 160-170. doi:10.1016/i.pbb.2007.12.008

[41] Pagan, O.R., Rowlands, A.L., Fattore, A.L., Coudron, T., Urban, K.R., Bidja, A.H. and Eterovic, V.A. (2009) A cembranoid from tobacco prevents the expression of nicotine-induced withdrawal behavior in planarian worms. European Journal of Pharmacology, 615, 118-124. doi:10.1016/j.ejphar.2009.05.022

[42] Pagan, O.R., Rowlands, A.L. and Urban, K.R. (2006) Toxicity and behavioral effects of dimethylsulfoxide in planaria. Neuroscience Letters, 407, 274-278. doi:10.1016/j.neulet.2006.08.073

[43] Pagan, O.R., Sivaprakasam, K. and Oswald, R.E. (2007) Molecular properties of local anesthetics as predictors of affinity for nicotinic acetylcholine receptors. Journal of Neuroscience Research, 85, 2943-2949. doi:10.1002/jnr.21402

[44] Nishimura, K., Kitamura, Y., Inoue, T., Umesono, Y., Sano, S., Yoshimoto, K., Inden, M., Takata, K., Taniguchi, T., Shimohama, S. and Agata, K. (2007) Reconstruction of dopaminergic neural network and locomotion function in planarian regenerates. Developmental Neurobiology, 67, 1059-1078. doi:10.1002/dneu.20377 